\title{
Clinical and urodynamic studies in 100 elderly incontinent patients
}

\author{
C M CASTLEDEN， H M DUFFIN， M J ASHER
}

\begin{abstract}
Clinical details were noted and urodynamic studies carried out on 100 elderly patients referred to an incontinence clinic, of whom 48 attended as day patients. Thirty patients had no problem apart from their incontinence, and only 38 had a clinically detectable neurological lesion. The average mental orientation score in 48 of the patients was $7 \cdot 6,23$ patients scoring the top score of 10 . Most patients were mobile without assistance from another person. Patients could be placed into one of four diagnostic groups according to the appearance of the cystometric tracings, but no bladder capacity or pressure was characteristic of any group. The maximum urethral closure pressure and functional profile length were similar for each group within each sex.

There was no correlation between clinical and urodynamic findings, yet each of the four diagnostic categories have different therapeutic implications.

It is concluded that urodynamic investigation is necessary in elderly incontinent patients before treatment.
\end{abstract}

\section{Introduction}

Urinary incontinence is present in $5 \cdot 7-11.0 \%$ of men and $13.9-$ $17.0 \%$ of women aged over 65 living in the community. ${ }^{1-3}$ It is even more common in patients in this age group in hospital, reaching $48 \%$ in some geriatric wards. ${ }^{4}$ In earlier reports authors suggested a close association with senile dementia, stroke, and immobility and concluded that cerebral lesions are the basic cause of incontinence in this age group. ${ }^{45}$ Identification of a region in the frontal lobe that was important in the control of micturition supported this hypothesis. ${ }^{6}$ ' An alternative suggestion, however, is that these studies were carried out almost entirely on patients in hospital, who reflected those in geriatric medical wards at that time. Furthermore, the most common cystometric finding in incontinent patients of any age is unstable detrusor contractions, ${ }^{5} 8$ and clinical studies in young adults with such lesions have shown no association with neurological conditions. ${ }^{8}$

Geriatric medical practice has altered appreciably over the past 15 years, and incontinence is now better understood and more easily investigated. We investigated 100 patients attending an incontinence clinic for the elderly, many of whom were clearly not demented or immobile, and report here on the aetiology and associated clinical features in these patients.

Leicester General Hospital, Leicester

C M CASTLEDEN, MD, MRCP, senior lecturer in geriatric medicine department of medicine

M J ASHER, technician, medical physics department

Leicester Area Health Authority (Teaching)

H M DUFFIN, SRN, staff nurse

\section{Methods}

We report the clinical and urodynamic features of 100 consecutive incontinent patients investigated in an incontinence clinic. All the patients were over 65 years and most had been referred by geriatricians, though a few had come via urologists and general physicians. If the patients were at home or in another hospital they came to the clinic on an outpatient basis, returning the same day.

\section{CLINICAL DETAILS}

The age, sex, and associated clinical conditions of each patient were noted. Mental orientation was assessed by a short, 10-question mental test in the last 48 subjects. 9 The best score is 10 and the worst 0 . Since the 52 other patients were investigated before this test was used routinely only a crude assessment of their mental orientation could be obtained from their notes; this was expressed as less than 5 or 5 and over. Mobility was classed as: independent; walked alone with an aid; walked with the help of one person; or needed two or more people.

\section{URODYNAMIC VARIABLES}

The methods of measuring urodynamic variables, their definitions, and the units in which they were expressed conform to the standards proposed by the International Continence Society except when specifically noted. ${ }^{10}$

Cystometry was performed as previously described. ${ }^{11}$ The bladder was filled continuously with physiological saline at body temperature. The rate $(50 \mathrm{ml} / \mathrm{min})$ was controlled by a Watson Marlow roller pump (MHRE 200) A double-lumen catheter (12F Portex) was inserted into the bladder and a fine $(2.5 \mathrm{~mm})$ catheter capped with a finger cot placed in the rectum. Pressure measurements from the bladder and rectal catheters, and the infused volume, were recorded on a GouldBrush 260 recorder. A Hewlett Packard (8848A) eight-channel power supply rack contained pressure amplifiers (8805C); a monitoring module; a strain-gauge amplifier to measure the volume infused into the bladder; and a subtraction amplifier, which subtracted rectal from measured intravesical pressure, thereby indicating the intrinsic bladder pressure. On the basis of this investigation patients' bladders were classed as (1) normal; (2) unstable: detrusor contraction exceeding $15 \mathrm{~cm}$ of water, which the patient could not inhibit; (3) atonic: patient unable to empty the bladder without manual aid; large residual; large capacity; no evidence of backpressure effects on ureters or kidneys; no obstruction to outflow; or (4) Irritable: patients often had a history of recurrent urinary tract infections with positive cultures from midstream specimens; pressure rose above baseline progressively but not evenly with increasing bladder volume.

The urethral pressure profile was measured by connecting the intravesical transducer to the catheter side holes along with an infusion line from a Vickers IP3 twin-carriage infusion pump set to deliver $2 \mathrm{ml} / \mathrm{min}$. The catheter was withdrawn at $0.5 \mathrm{~cm} / \mathrm{s}$, movement being displayed on the chart. Bladder pressure was measured via the catheter end hole during withdrawal and subtracted from the urethral pressure. The result displayed was the urethral closure pressure, from which the maximum urethral closure pressure and the functional profile length were noted.

\section{Results}

\section{CLINICAL DETAILS}

Thirty-eight patients were investigated as outpatients; a further 10 were inpatients in other hospitals. Table I shows the relation between 
cystometric diagnosis and age and sex. The five most common associated clinical conditions were established for each cystometric diagnosis. Some patients had more than one associated condition. Of the 16 patients with normal bladders, five had no associated condition, three were confused or demented, and three had had a stroke; five others each had one other associated condition. Of the 68 patients with unstable bladders, 21 had no associated medical condition, 13 were confused or demented, 13 had had a stroke, six suffered from impaction or constipation, and four had diabetes mellitus. Of the 11 patients

TABLE I-Relation between cystometric diagnosis and age and sex in 100 incontinent patients

\begin{tabular}{|c|c|c|c|c|c|c|c|c|c|c|c|c|c|}
\hline \multirow{3}{*}{$\begin{array}{c}\text { Age } \\
\text { (years) }\end{array}$} & \multicolumn{12}{|c|}{ Cystometric diagnosis } & \multirow{3}{*}{ Total } \\
\hline & \multicolumn{3}{|c|}{ Normal } & \multicolumn{3}{|c|}{ Unstable } & \multicolumn{3}{|c|}{ Atonic } & \multicolumn{3}{|c|}{ Irritable } & \\
\hline & $\mathbf{M}$ & $\mathbf{F}$ & Total & $\bar{M}$ & $F$ & Total & $\bar{M}$ & $F$ & Total & $\bar{M}$ & $\mathrm{~F}$ & Total & \\
\hline $\begin{array}{l}65-74 \\
75-84 \\
85-94\end{array}$ & 1 & $\begin{array}{l}6 \\
7 \\
2 \\
\end{array}$ & $\begin{array}{l}6 \\
8 \\
2\end{array}$ & $\begin{array}{l}8 \\
8 \\
6\end{array}$ & $\begin{array}{r}9 \\
17 \\
20\end{array}$ & $\begin{array}{l}17 \\
25 \\
26\end{array}$ & 2 & $\begin{array}{l}3 \\
3 \\
3\end{array}$ & $\begin{array}{l}5 \\
3 \\
3\end{array}$ & & 5 & 5 & $\begin{array}{l}28 \\
41 \\
31\end{array}$ \\
\hline Total & 1 & 15 & 16 & 22 & 46 & 68 & 2 & 9 & 11 & & 5 & 5 & 100 \\
\hline
\end{tabular}

TABLE II-Number of patients scoring less than 5 or 5 and more in mental orientation test

\begin{tabular}{rcccccr}
\hline \multirow{2}{*}{ Score } & \multicolumn{5}{c}{ Cystometric diagnosis } \\
\cline { 2 - 6 } & Normal & Unstable & Atonic & Irritable & Total \\
\hline 5 & 11 & 37 & 7 & 2 & 57 \\
5 & 5 & 30 & 4 & 3 & 42 \\
Not recorded & 16 & 68 & 11 & 5 & 100 \\
\hline Total & & & & &
\end{tabular}

TABLE III-Mental orientation scores of 23 patients with unstable detrusor contractions $(0=$ worst, $10=$ best $)$

\begin{tabular}{llllllllllll}
\hline Mental score: & 0 & 1 & 2 & 3 & 4 & 5 & 6 & 7 & 8 & 9 & 10 \\
No of patients: & 1 & & & & 1 & 1 & 2 & 2 & 2 & 3 & 11
\end{tabular}

TABLE IV-Relation between mobility and cystometric diagnosis in all 100 patients $(1=$ independent $; 2=$ walked alone with aid $3=$ walked with help of one person $; 4=$ needed two or more people)

\begin{tabular}{crrrr}
\hline \multirow{2}{*}{$\begin{array}{c}\text { Mobility } \\
\text { rating }\end{array}$} & \multicolumn{5}{c}{ Cystometric diagnosis } \\
\cline { 2 - 5 } & Normal & Unstable & Atonic & Irritable \\
\hline 1 & 8 & 26 & 6 & 2 \\
2 & 7 & 32 & 2 & 3 \\
3 & 1 & 8 & 3 & \\
4 & & 1 & & \\
\hline
\end{tabular}

with atonic bladders, three had no associated condition, two had breast cancer, two depression, and two osteoarthritis or rheumatoid arthritis; four other patients each had one other associated condition. Finally, of the five patients with irritable bladders, one had no associated condition, one confusion, one stroke, one impaction, and one diabetes mellitus. Thus 30 patients had no problem apart from incontinence, and 38 had a clinically detectable neurological lesion including senile dementia.

Mental orientation-Table II shows the assessment of mental orientation for each diagnosis. Over half of all the patients scored 5 and over. The average accurate score was $7 \cdot 6$ (range $0-10$ ) in all 48 patients and $8 \cdot 1$ (range $0-10$ ) in 23 patients with an unstable bladder (table III). There was no correlation between the mental test score and any urodynamic measurement in patients with unstable bladders.

Mobility-Table IV shows the relation between mobility and cystometric diagnosis. Most patients were independent with or without an aid.
TABLE v-Bladder volume and pressure at capacity and urethral pressure in patients grouped according to cystometric diagnosis

\begin{tabular}{|c|c|c|c|c|}
\hline & \multicolumn{4}{|c|}{ Cystometric diagnosis } \\
\hline & Normal & Unstable & Atonic & Irritable \\
\hline $\begin{array}{c}\text { Volume at capacity }(\mathrm{ml}): \\
0-99 \\
100-199 \\
200-299 \\
300-399 \\
400-499 \\
500-599 \\
600-699 \\
700-799 \\
800-899 \\
900-999 \\
1000+\end{array}$ & $\begin{array}{l}1 \\
1 \\
3 \\
6 \\
3 \\
2\end{array}$ & $\begin{array}{r}7 \\
14 \\
27 \\
12 \\
5 \\
1 \\
2\end{array}$ & $\begin{array}{l}4 \\
3 \\
1 \\
3\end{array}$ & $\begin{array}{l}1 \\
2 \\
1 \\
1\end{array}$ \\
\hline $\begin{array}{c}\text { Pressure at capacity }\left(\mathrm{cm} \mathrm{H}_{2} \mathrm{O}\right) \text { : } \\
0-19 \\
20-39 \\
40-59 \\
60-79 \\
80-99 \\
100+\end{array}$ & $\begin{array}{r}13 \\
3\end{array}$ & $\begin{array}{r}8 \\
27 \\
17 \\
6 \\
4 \\
6\end{array}$ & $\begin{array}{l}6 \\
3 \\
1 \\
1\end{array}$ & $\begin{array}{l}3 \\
1 \\
1\end{array}$ \\
\hline $\begin{array}{c}\text { Urethral pressure }\left(\mathrm{cm} \mathrm{H}_{2} \mathrm{O}\right): \\
0-19 \\
20-39 \\
40-59 \\
60-79 \\
80-99 \\
100+\end{array}$ & $\begin{array}{l}9 \\
4 \\
1\end{array}$ & $\begin{array}{r}9 \\
25 \\
18 \\
7 \\
5\end{array}$ & $\begin{array}{l}2 \\
4 \\
3 \\
2\end{array}$ & $\begin{array}{l}1 \\
2 \\
2\end{array}$ \\
\hline
\end{tabular}

\section{URODYNAMIC DATA}

Table V shows the bladder volumes and pressures at capacity and $\vec{C}$ the urethral pressures for each group.

Bladder capacity-Three-quarters of the patients with a normal bladder $(12 / 16)$ had a bladder capacity of between 300 and $600 \mathrm{ml}$, whereas three-quarters of those with unstable contractions $(53 / 68)$ had a capacity of $100-400 \mathrm{ml}$. There was considerable overlap, except that no patient with a normal bladder had a capacity of under $100 \mathrm{ml}$. Seven of the 11 patients with atonic bladders had capacities of over $700 \mathrm{ml}$; this size was not found in any other group.

Pressure at capacity-Four patients with unstable bladders had pressures at capacity of below $13 \mathrm{~cm} \mathrm{H}_{2} \mathrm{O}$. Very high pressures $\left(>60 \mathrm{~cm} \mathrm{H} \mathrm{H}_{2} \mathrm{O}\right.$ ) were seen only in patients with unstable bladders, except in one man with an atonic bladder $\left(80 \mathrm{~cm} \mathrm{H}_{2} \mathrm{O}\right)$. Outflow obstruction was excluded in this patient by cystoscopy and the urethral pressure profile was normal.

Maximum urethral closure pressures were similar in all groups. Although two patients with unstable bladders had pressures of less than $10 \mathrm{~cm} \mathrm{H}_{2} \mathrm{O}$, most patients had pressures of over $20 \mathrm{~cm} \mathrm{H}_{2} \mathrm{O}$. The highest recorded pressure was $90 \mathrm{~cm} \mathrm{H}_{2} \mathrm{O}$, in a patient with an unstable bladder; and of 15 patients with pressures of more than $60 \mathrm{~cm} \mathrm{H} \mathrm{H}_{2} \mathrm{O}, 12$ had unstable contractions. There was no correlation between the pressure at capacity and maximum urethral closure pressure.

Functional urethral profile length-There was no difference between the groups in the functional urethral profile length. The length in men was on average three times longer than that in women (table VI).

TABLE VI-Functional urethral length in 91 of the 100 patients related to sex and cystometric diagnosis

\begin{tabular}{|c|c|c|c|c|}
\hline \multirow{2}{*}{$\begin{array}{l}\text { Cystometric } \\
\text { diagnosis }\end{array}$} & \multirow{2}{*}{ Sex } & \multirow{2}{*}{ No of patients } & \multicolumn{2}{|c|}{$\begin{array}{l}\text { Functional urethral } \\
\text { length }(\mathrm{cm})\end{array}$} \\
\hline & & & Mean & Range \\
\hline Normal & $\left\{\begin{array}{l}\mathrm{F} \\
\mathrm{M}\end{array}\right.$ & $\begin{array}{r}13 \\
1\end{array}$ & $\begin{array}{r}3 \cdot 0 \\
10.6\end{array}$ & $1 \cdot 7-4 \cdot 6$ \\
\hline & & 43 & $2 \cdot 8$ & $1 \cdot 0-4 \cdot 2$ \\
\hline Unstable & M & 18 & $9 \cdot 7$ & $3 \cdot 4-18 \cdot 0$ \\
\hline Irritable & $\mathrm{F}$ & 5 & $2 \cdot 8$ & $2 \cdot 1-3 \cdot 4$ \\
\hline Atonic & $\left\{\begin{array}{l}F \\
M\end{array}\right.$ & $\begin{array}{l}9 \\
2\end{array}$ & $\begin{array}{l}3 \cdot 2 \\
8 \cdot 6\end{array}$ & $\begin{array}{l}2 \cdot 0-3 \cdot 8 \\
1 \cdot 7-15 \cdot 5\end{array}$ \\
\hline
\end{tabular}

Volume and pressure of first contraction-In 27 patients with unstable contraction's the first spasm was at capacity. The mean volume in those in whom the first spasm occurred before capacity was $204 \mathrm{ml}$ (range $24-480 \mathrm{ml}$ ), and the mean pressure was 25 (range 4-72) $\mathrm{cm} \mathrm{H}_{2} \mathrm{O}$. This pressure was considerably lower than the pressure at 
capacity in the same patients (mean $66 \mathrm{~cm} \mathrm{H}_{2} \mathrm{O}$; range 23-160). There was no correlation between the pressures or volumes at first spasm and those at capacity in these patients.

\section{Discussion}

These results show that urinary incontinence in most elderly patients is not associated with immobility and cerebral disease. The only other study in elderly patients was reported in 1966 and included only women, almost all of whom were inpatients ${ }^{5}$ $83 \%$ had a primary diagnosis of neurological disease, either stroke or dementia, and the authors concluded that cerebral lesions were the basic cause of urinary incontinence. This was reinforced by results of another study on incontinence on 522 patients in a geriatric hospital. ${ }^{*}$ Although cystometry was not performed, clinical assessment showed a close association between the occurrence and severity of urinary incontinence and mental and physical ability. The discrepancy between these observations and those reported here may be explained by the source of the patients selected for study.

In the present study 48 patients attended as day patients for urodynamic investigation: 38 were outpatients and 10 inpatients in other hospitals. Although the patients were still selected, they were considerably different from those in geriatric medical wards 15 or more years ago. The present results suggest that incontinence is not caused by cerebral disease in most elderly patients. The cystometric studies lend additional support for this contention. The most common urodynamic finding in these patients was the presence of unstable detrusor contractions at the time of incontinence. This association has been reported before in elderly patients, and in enuretic patients aged 10-49 years. ${ }^{8}$ No associated neurological or psychiatric deficit was found in any of the younger patients. Thirty elderly patients in the present study with unstable contractions had no other clinical problem and two further patients had unassociated orthopaedic lesions. Ten more patients in this group suffered from impaction and constipation, which might suggest an associated abnormality in large-bowel behaviour or imply a local cause for unstable detrusor contractions.

All patients were assessed before cystometric investigation by the nurse attached to the unit. There is thus no reason to admit elderly incontinent patients for investigation unless they live alone and are confused. There were more women than men in each diagnostic category, which reflects the preponderance of older women in general and the greater prevalence of urinary incontinence in women. ${ }^{1-3}$

Patients could be placed into one of four diagnostic categories according to the appearance of the cystometric trace. Overall, no bladder capacity or pressure appeared to be characteristic of any condition including normality, although only patients with atonic bladders had capacities in excess of $700 \mathrm{ml}$ and the pressure at capacity in patients with normal bladders did not exceed $25 \mathrm{~cm} \mathrm{H}_{2} \mathrm{O}$. Only 16 patients had normal bladders, however, and some caution is needed before extrapolating these results to other elderly patients with normal bladders. In general the capacity in elderly patients with unstable contractions is lower than normal, and most often below that found by Jarvis and Millar $^{12}$ to respond successfully to toileting regimens alone. There was no difference between the volume at capacity and that at first spasm in about half the patients with unstable contraction. This indicates that they would have little warning of impending micturition since contraction would occur before their normal bladder capacity had been reached. The patient therefore would receive no warning of the contraction until the pressure had already started to rise. This is so swift (only a few seconds from start to peak) that urine would appear at the meatus almost simultaneously with recognition of increasing bladder tone.

The maximum urethral closure pressure and functional profile length were remarkably constant between all four conditions within each sex. Thus both measurements have no diagnostic importance in most incontinent patients. Individually, however, these variables may be therapeutically important, particularly in assessing the effect of drug treatment.

As in other studies there was no correlation between signs, symptoms, and urodynamic findings, nor between one urodynamic finding and another. Sixteen patients had normal bladders, although all had been referred for investigation of incontinence. In almost all this was explained by a transient illness that had cleared by the time of investigation; senile dementia, when the patient could not remember either to go to the toilet or where the toilet was; depression, when the patient could not be bothered to go to the toilet; or immobility owing to a stroke, recent fracture, or amputation.

In conclusion, this study shows that categorisation of elderly incontinent patients is possible and may be carried out on an outpatient basis. Rational treatment may therefore be given with confidence for specific conditions. Although many geriatric medical units do not have access to urodynamic apparatus and many patients in centres with such facilities are not referred for investigation, ${ }^{13}$ we regard treatment of urinary incontinence in the elderly without prior cystometry synonymous with that of treating cardiac arrhythmias without electrocardiography.

We are most grateful to Dr C A Kraft for help in analysing the results.

\section{References}

${ }^{1}$ Feneley RCL, Shepherd AM, Powell PH, Blannin J. Urinary incontinence : prevalence and needs. Brf Urol 1979;51:493-6.

2 Yarnell JWG, St Leger AS. The prevalence, severity and factors associated with urinary incontinence in a random sample of the elderly. Age Ageing 1979;8:81-5.

3 Thomas TM, Plymat KR, Blannin J, Meade TW. Prevalence of urinary incontinence. $\mathrm{Br} \mathrm{Med}$ F $1980 ; 281: 1243-5$.

4 Isaacs B, Walkey FA. A survey of incontinence in elderly hospital patients. Gerontologia Clinica 1964 ;6:367-376.

5 Brocklehurst JC, Dillane JB. Studies of the female bladder in old age. II. Cystometrograms in 100 incontinent women. Gerontologia Clinica $1966 ; 8: 306-319$

6 Tang P-C, Ruch TC. Non-neurogenic basis of bladder tonus. Am $\mathcal{F}$ Physiol 1955;181:249-57.

7 Andrew J, Nathan PW. Lesions of the anterior frontal lobes and disturbances of micturition and defaecation. Brain $1964 ; 87: 233-62$.

8 Torrens MJ, Collins CD. The urodynamic assessment of adult enuresis. Br F Urol 1975;47:433-40.

${ }^{9}$ Qureshi KN, Hodkinson HM. Evaluation of a ten-question mental test in the institutionalised elderly. Age Ageing 1974;3:152-7.

10 Bates P, Bradley WE, Glen E, et al. The standardization of terminology of lower urinary tract function. 7 Urol 1979;121:551-4.

${ }^{11}$ Briggs RS, Castleden CM, Asher MJ. The effects of flavoxate on uninhibited detrusor contractions and urinary incontinence in the elderly. 7 Urol 1980;123:665-6.

12 Jarvis GJ, Millar DR. Controlled trial of bladder drill for detrusor instability. Br Med f $1980 ; 281: 1322-3$.

${ }^{13}$ Isaacs B. The management of urinary incontinence by departments of geriatric medicine. Health Trends 1979;11:42-4.

(Accepted 3 February 1981)

ONE HUNDRED YEARS AGO Dr William $S$ Hills writes to the Boston Medical and Surgical fournal, for January 13th, in deprecation of the nitrate of silver test as the "most simple and reliable test for arsenic in wall-papers." He states, and gives reasons at length for his opinion, that it is, on the contrary, one of the least reliable tests for the purpose. He then gives his own method, which is as follows. Take a sample three or four inches square (less will suffice with plain papers), cut into small pieces, moisten with concentrated sulphuric acid, and heat carefully till the paper is thoroughly charred. Let the charred mass cool, add to it about one fluid ounce of water, grind the black mass fine that the water may come into contact with all parts of it, filter, and wash. The arsenic will be found in the filtrate, which is examined by Marsh's test. All the chemicals must be free from arsenic. A paper which, treated carefully in this manner, furnishes no arsenical mirror on porcelain, does not contain any appreciable amount of arsenic. (British Medical fournal, 1881.) 